Invited Review/Perspective

Chromosome Research special issue on "Genome and Chromosome Engineering"

\title{
Human Artificial Chromosomes for Duchenne Muscular Dystrophy and Beyond: Challenges and Hopes
}

\author{
Francesco Saverio Tedesco, MD PhD \\ Department of Cell and Developmental Biology, University College London \\ 21 University Street WC1E 6DE London, UK \\ Tel: +44 (0)2031082383 \\ Fax: +44 (0) 2076797349 \\ Correspondence (email): f.s.tedesco@ucl.ac.uk.
}

\section{Running Title}

HACs for gene therapy of muscular dystrophy

\section{Keywords}

Human Artificial Chromosome; muscular dystrophy; stem cells; gene therapy; cell therapy.

\section{List of Abbreviations}

AAV: adeno-associated viral (vectors);

cDNA: complementary DNA;

CHO: Chinese hamster ovary (cells);

DMD: Duchenne muscular dystrophy;

DT40: chicken B cell line (lymphoblasts);

DYS-HAC: dystrophin-HAC;

GFP: green fluorescent protein;

HAC: human artificial chromosome;

iPS: induced-pluripotent stem (cells);

MMCT: microcell-mediated chromosome transfer;

PEG: polyethylene glycol.

\begin{abstract}
Safe and efficacious vectors able to carry large or several transgenes are of key importance for gene therapy. Human artificial chromosomes can fulfil this essential requirement; moreover, they do not integrate into the host genome. However, drawbacks such as the low efficiency of chromosome transfer and their relatively complex engineering still limit their widespread use. In this article I summarise the key steps that brought human artificial chromosomes into preclinical research for Duchenne muscular dystrophy, an X-linked, monogenic disorder I will also review possible future pre-clinical and clinical perspectives for this technology.
\end{abstract}

Duchenne muscular dystrophy: a major challenge for gene therapy 
Duchenne muscular dystrophy (DMD) is among the most common human paediatric monogenic disorders, affecting $1 / 5,000$ male births. Almost thirty years have passed since the discovery that DMD was caused by mutations in the dystrophin gene on the $X$ chromosome (Hoffman et al., 1987). Dystrophin mutations cause progressive muscle degeneration, wasting and weakness. This results in loss of motility, respiratory and cardiac failure and, ultimately, death (Mercuri and Muntoni, 2013). No cure is currently available for DMD and the search for possible therapies is challenging generations of clinicians and scientists. Nevertheless, several strategies are undergoing experimental testing, with some of them in promising phase II or III clinical trials (Benedetti et al., 2013). Among these, gene replacement is still an attractive option in light of large deletions or mutations in critical domains of the protein that preclude the use of shorter functional versions of the dystrophin protein, such as those generated by antisense oligonucleotide-mediated exonskipping (Muntoni and Wood, 2011; Benedetti et al., 2013). Moreover, after years of assiduous research, gene therapy is now delivering excellent clinical results (Aiuti et al., 2009; Gaspar et al., 2011; Biffi et al., 2013).

However, specific hurdles slowing down major progress in DMD gene therapy are: 1) Dystrophin is the largest human gene $(2.4 \mathrm{Mb})$ with a complex transcriptional regulation (Muntoni et al., 2003); 2) Even dystrophin full cDNA (14 kb) cannot be accommodated inside conventional vectors that allow stable gene expression in dividing and non dividing cells; 3 ) The main tissue affected in DMD is skeletal muscle, which is also the most abundant tissue of the human body; this means that the transgene needs to target a reasonable high number of nuclei to provide some efficacy; 4) Increasing evidence shows exhaustion or dysfunction of dystrophic stem/progenitor cells, necessary for ex vivo gene therapy (Blau et al., 1983; Cohn et al., 2002; Sacco et al., 2010; Cassano et al., 2011; Kudryashova et al., 2012; Tedesco et al., 2012); 5) Brain and heart are also affected in DMD; this together with the widespread distribution of skeletal muscle poses additional hurdles for the delivery of the transgene.

Therefore, a large cargo vector with a safe and stable expression profile would be an ideal candidate to bypass most of the aforementioned limitations. In this review I will summarise the evidence that brought human artificial chromosomes (HACs) into DMD gene therapy, analysing advantages and disadvantages of this platform for skeletal muscle repair and regeneration. I will not analyse previous and current use of HACs for pharmaceutical applications, animal transgenesis and cytogenetic studies, for which I redirect the reader to excellent reviews in other journals (Kazuki and Oshimura, 2011; Kouprina et al., 2014) and in this special issue.

\section{Too Big to Transfer, Too Much to Fix}

Initial attempts to transfer the entire dystrophin cDNA were based upon direct intramuscular injection of cDNAs in mdx mice, which model DMD (Bulfield et al., 1984; Acsadi et al., 1991). Although plasmids provided a proof-of-principle that transfer of the entire cDNA restores dystrophin in some myofibres, it was soon clear that delivery of the plasmid to all muscles would be a major challenge. Moreover, immunological issues related to direct DNA transfer into muscle added another layer of complexity to the strategy. Two possible options were available at this point: 1) To 
shorten the cDNA size, so that it could be inserted into a viral vector with more efficient transfer rate (although immunity, delivery and presence of functional skeletal muscle would still be issues); 2) To use muscle stem cells as a "trojan horse" to transfer the whole gene to skeletal myofibres (gene and cell therapy). This last approach proved to be promising following seminal work of Partridge and colleagues in 1989, demonstrating generation of dystrophin-positive myofibres after normal donor myoblast transplantation in mdx mice (Partridge et al., 1989). However, when a similar approach was undertaken in human clinical trials, allogeneic myoblast transplantation showed safety but not functional clinical efficacy in DMD patients (Partridge, 2002; Tedesco et al., 2010; Skuk and Tremblay, 2014). For this reason and to avoid immune-suppressive therapy for allogeneic transplants (reviewed in (Maffioletti et al., 2014)), several groups turned their attention back to gene transfer in $\mathrm{DMD}$, either directly into muscle or via ex vivo correction of dystrophic muscle stem/progenitor cells.

However, the choice of an ideal muscle stem cell candidate also posed some hurdles, as the limitations of myoblasts for systemic delivery redirected the attention of the muscle community towards alternative and non-conventional myogenic progenitors different from satellite cells/myoblasts (Benedetti et al., 2013). One of these cell types, called mesoangioblast, was identified initially in the embryonic vessel wall of the dorsal aorta and subsequently its adult counterpart was identified in a subset of skeletal muscle pericytes (Minasi et al., 2002; Dellavalle et al., 2007). These cells have been shown to contribute also to normal skeletal muscle development (Dellavalle et al., 2011) and when delivered intramuscularly or intraarterially in dystrophic animal models they ameliorated muscle morphology and function (reviewed in (Benedetti et al., 2013)). Based upon this pre-clinical evidence a clinical trial to test their safety has been recently completed in five Duchenne boys (EudraCT no. 2011-000176-33; www.clinicaltrialsregister.eu). This trial is based upon infusion of HLA-matched allogeneic donor pericytes/mesoangioblasts. The need to translate this strategy to an autologous setting prompted the search for a possible candidate vector for DMD therapy that would allow transfer of the entire dystrophin gene without the risk of insertional mutagenesis (Biasco et al., 2012).

\section{Engineering Human Artificial Chromosomes (HACs)}

An alternative approach to the "shortening" of a specific gene/cDNA to allow its accommodation into a vector is to increase the cargo capacity of the vector itself. This strategy would fit perfectly with the large size of dystrophin. TO achieve this aim, Oshimura and his group pioneered the engineering of a HAC containing the entire dystrophin genetic locus (DYS-HAC) (Hoshiya et al., 2009).

HACs are exogenous mini-chromosomes generated either by a "bottomup"/de novo strategy (Mandegar et al., 2011; Kononenko et al., 2014) or engineered by a "top-down approach" (engineered chromosomes) (Kazuki et al., 2011). They remain episomal (i.e. not integrated) in the host genome and get replicated and segregated during mitosis as supernumerary mini-chromosomes. This prevents silencing of the transgene due to possible positional effect, interference with endogenous gene expression and, most importantly, cell transformation due to insertional mutagenesis. 
A top-down approach was utilized to engineer the DYS-HAC (Hoshiya et al 2009). Human chromosome 21 was "deconstructed" of all its endogenous genes and utilized as HAC "backbone" (Kazuki et al., 2011). In parallel, a fragment of the human $X$ chromosome containing its short arm was transferred into the homologous recombination-proficient chicken DT40 cell line and a loxP cassette was targeted proximally to the human dystrophin locus. Distal endogenous $\mathrm{X}$-chromosome genes were removed by telomere-associated chromosome truncation. This modified $X$ fragment was transferred into Chinese hamster ovary $(\mathrm{CHO})$ cells containing the above HAC using a PEG fusion-based technique called microcell-mediated chromosome transfer (MMCT) (Fournier and Ruddle, 1977; Uno et al., 2013). As a result, the entire dystrophin $2.4 \mathrm{Mb}$ genetic locus was cloned into the HAC vector by Cre-loxP mediated chromosomal translocation. At this stage the so-called "DYS-HAC" was ready to be tested and transferred to target cells. To this aim the resulting $\mathrm{CHO}$ hybrids were expanded, characterized and enucleated to generate microcells for MMCT to target cells, which after DYS-HAC transfer in turn expanded under selection drugs and then screened for the presence of an episomal and stable HAC.

\section{Stem/Progenitor Cells: HAC's Troy Horse}

The first candidates to test the DYS-HAC were mouse embryonic stem cells, with whom trans-chromosomic mice expressing the different isoforms of human dystrophin were generated as a proof-of-principle of its function in vivo (Hoshiya et al., 2009). Even though the DYS-HAC was also transferred into human mesenchymal stem cells (Hoshiya et al., 2009), these cells have shown not to be an ideal candidate for the cell therapy of muscular dystrophy (Gang et al., 2009). To achieve this aim the DYS-HAC was transferred into mesoangioblasts isolated from $\mathrm{mdx}$ mice and the resulting genetically corrected cells were transplanted into dystrophic and immunedeficient scid/mdx mice, to avoid rejection caused by the presence of the human dystrophin and other HAC transgenes (e.g. GFP). Remarkably, transplanted animals showed morphological and functional amelioration of the dystrophic phenotype. This was the first evidence of HAC-mediated gene therapy strategy that resulted in a safe and efficacious outcome of a genetic disease (Tedesco et al., 2011).

In parallel, Kazuki, Oshimura and colleagues transferred the same DYS-HAC into iPS cells derived from DMD patients (Kazuki et al., 2010) and the resulting iPS cells were also differentiated into pericyte/mesoangioblast-like myogenic progenitors, which correctly expressed human dystrophin (Tedesco et al., 2012). More recently, DYS-HAC-corrected DMD iPS cells have also been successfully differentiated into cardiomyocytes, which correctly expressed the different dystrophin isoforms during the differentiation process (Zatti et al., 2014). We are currently focusing our efforts to extend the DYS-HAC-based platform to human muscle-derived stem/progenitor cells and to iPS cells generated and differentiated with novel and safer integration-free strategies. Notably, the use of tissue-derived progenitors requires one additional step necessary to extend cell proliferation to survive the clonal process of HAC transfer. To this aim we have engineered muscle progenitors with excisable lentiviral vectors expressing immortalizing genes and safety/suicide cassettes in a reversible fashion, so that the cells will sustain expansion to numbers compatible with those necessary to treat a patient (i.e. in the range of $10^{9}$ cells; Benedetti et al., in preparation). In parallel, in case the isolation of 
muscle stem/progenitor cells results difficult from a muscle biopsy, myogenic progenitors can be derived from human iPS cells (Darabi et al., 2012; Goudenege et al., 2012; Tedesco et al., 2012; Borchin et al., 2013; Tanaka et al., 2013; Xu et al., 2013).

\section{Current Challenges and Future Perspectives}

HAC-based gene therapy promises to overcome space limitation issues of current vectors and the risk of mutagenesis following integration into host genome. This is particularly attractive for skeletal muscle gene therapy, as the large cargo capacity of HACs could provide a feasible solution to increase gene expression in myofibers. Skeletal myofibres are indeed syncitia containing several post-mitotic nuclei. Therefore, in the case of a recessive disease, the possibility to have one geneticallycorrected nucleus carrying more than one copy of the gene of interest could provide a way to decrease the number of cells to transplant, without decreasing the possible efficacy (effectively increasing gene-dosage and safety). However, this approach is still limited to ex vivo correction, as direct HAC transfer in vivo faces the limitation of the presence of xenogeneic chromosomes from the donor cell line inside the microcells. Active research is currently on going to develop strategies that can overcome this limitation (Mitsuo Oshimura, personal communication).

Even though the HAC transfer is limited to ex vivo correction of stem/progenitor cells, the use of "clinical-friendly" reagents and protocols will be critical to accelerate the possible clinical translation of this platform, which still relies on the use of chicken DT40 cells to engineer the HAC and rodent cells ( $\mathrm{CHO}$ or mouse A9 cells) to generate microcells. CRISPR/CAS9 technology (Hsu et al., 2014) could be extremely valuable to avoid the need of homologous recombination in DT40 cells. Ad hoc approval of rodent cell lines to support generation of medicinal products for human cell therapy has already been successfully done for cornea and skin transplants (Mavilio et al., 2006; Rama et al., 2010) and could be a feasible ad interim solution for clinical translation of HACs. Another area of active studies concerns the delivery of corrected cells. Mesoangioblasts are currently delivered in the arterial circulation via femoral artery injection (mice) or catheterisation (humans). However, this still does not allow targeting of the diaphragm, heart, spinal muscles and muscles of the pelvic girdle (critical for ambulation). It is foreseeable that the rapidly evolving fields of interventional radiology and cardiology could supply technical advances and new devices that will overcome current limitations of cell delivery to dystrophic muscles.

Overall, the HAC pathway to clinical translation is not expected to be more difficult or challenging than that of other viral vectors (Narayanan et al., 2014). Nevertheless, it is expected that the presence of a supernumerary (non pathogenic) chromosome in cells candidate for a transplant will require stringent safety studies in large animal models. This scenario will also need to be considered in the context of a possible need for a mild immune suppression in Duchenne boys undergoing autologous transplants, as T cells primed to recognize dystrophin epitopes have been reported in a significant number of patients with DMD (approximately $20 \%$ steroid-treated and 50\% steroid-naive) (Mendell et al., 2010a; Flanigan et al., 2013).

In recent years several gene repair/replacement strategies became available for DMD (Benedetti et al 2013). Some of them, such as antisense oligonucleotide- 
mediated exon-skipping and the use of quasi-dystrophins, result in the generation of a shorter protein that should retain most of the functions of the full-length dystrophin. Even though exon-skipping for DMD has been tested in phase III clinical trials (NCT01254019, www.clinicaltrials.gov) this remains a mutation-specific strategy, hence not applicable to large deletions and to mutations in strategic domains of the gene/protein (Aartsma-Rus et al., 2009). Similar short-/quasidystrophins have been delivered to muscle using adeno-associated viral (AAV) vectors (Harper et al., 2002). The immunological profile of AAV vectors is still a matter of active clinical investigation (Mendell et al., 2010a; Mendell et al., 2010b) as it is their integration safety profile (Schultz and Chamberlain, 2008; Smith, 2008; Kaeppel et al., 2013; Cogne et al., 2014). A recent strategy based upon triple transsplicing AAV vectors provides a possible solution to transfer the full-length dystrophin cDNA, thus overcoming the $4.7 \mathrm{~kb}$ single-AAV packaging capacity (Koo et al., 2014). Nevertheless, another recent report shows that AAV vectors do not efficiently target muscle satellite stem cells in vivo, thus limiting their effect to postmitotic myonuclei (assuming muscle tissue architecture is preserved) and not to the stem cell compartment (Arnett et al., 2014). Transposons promise to deliver large genes efficaciously. They could accommodate the entire dystrophin cDNA (but not the entire locus) and, similarly to HACs, are not directly deliverable to muscle but limited to ex vivo gene correction (Di Matteo et al., 2012). Although some transposon systems have been already manufactured under clinical-grade conditions (Singh et al., 2013) and should not require a clonal selection of the corrected cell population, efficacy and insertional mutagenesis in human cells following introduction of large genes, such as dystrophin, will need to be carefully evaluated in specific studies (Hackett et al., 2013).

What's beyond DMD for HAC-mediated gene therapy? Certainly the scenario is complex and the competing strategies are many (Naldini, 2011). Mutations in large genes other than dystrophin will benefit from the pre-clinical work conducted in DMD. An example of this could be in dysferlinopathies, a group of different autosomal recessive muscular dystrophies caused by mutations in the 55 exons long dysferlin gene, whose cDNA size (6.2 kb, not including expression-control elements) challenges the cloning capacity of viral vectors (Barthelemy et al., 2011). Importantly, preclinical work has been done using muscle stem cell transplantation in a mouse model of dysferlynopathy (Diaz-Manera et al., 2010). Diseases in tissues other than muscle could also be candidate for HAC-mediated gene therapy. This is particularly relevant for genes/loci requiring complex regulation, such as the globins and the relative haemoglobinopathies or for disorders of red blood cells such as recessive spherocytosis, where the mutated gene - alpha spectrin - is related to dystrophin in terms of evolution, size and function (Broderick and Winder, 2005). The deep knowledge on haematopoietic stem cell biology and transplantation would be a major plus for ex vivo gene therapy of this subset of disorders. Finally, the space on the HAC could also be exploited to accommodate more than one gene, different gene functions or several copies of the same gene, as was shown for factor VIII deficiency and haemophilia A (Kurosaki et al., 2011).

\section{Conclusions}


The field of human artificial chromosome engineering has experienced considerable progress from its initial studies of gene function and animal transgenesis. HAC translational potential for gene therapy has been demonstrated for DMD, but several other disorders might be amenable to have a similar approach. It is possible that the active research in DMD and its critical need for a therapy will also accelerate technological advances to overcome current bottlenecks that prevent widespread use of this platform for gene replacement therapies. Even though sometimes in life and science "less is more", we cannot ignore that in gene therapy size matters: hopefully HACs will be ready to address this issue in clinical trials in a not so distant future.

\section{Acknowledgements}

The author thanks Mitsuo Oshimura, Narumi Uno, Yasuhiro Kazuki, Giulio Cossu, Hidetoshi Hoshiya and all laboratory members for the active discussions on HAC technology and the helpful suggestions on the manuscript. Work in the author's laboratory is supported by the UK Medical Research Council (MRC grants no. MR/J006785/1 and MR/L002752/1), Duchenne Parent Project Onlus, European Union's $7^{\text {th }}$ Framework Programme (PluriMes project, grant no. 602423), Takeda New Frontier Science, Biotechnology and Biological Sciences Research Council (BBSRC), Muscular Dystrophy Campaign, Duchenne Children's Trust and the Duchenne Research Fund.

\section{Conflict of interest}

The author does not have any financial relationships with the funding bodies that sponsored the research in his laboratory, therefore he declares no conflict of interest.

\section{References}

Aartsma-Rus A, Fokkema, I, Verschuuren, J, Ginjaar, I, Van Deutekom, J, Van Ommen, G J \& Den Dunnen, J T (2009) Theoretic applicability of antisensemediated exon skipping for Duchenne muscular dystrophy mutations. Hum Mutat, 30, 293-9.

Acsadi G, Dickson, G, Love, D R, Jani, A, Walsh, F S, Gurusinghe, A, Wolff, J A \& Davies, K E (1991) Human dystrophin expression in mdx mice after intramuscular injection of DNA constructs. Nature, 352, 815-8.

Aiuti A, Cattaneo, F, Galimberti, S, Benninghoff, U, Cassani, B, Callegaro, L, Scaramuzza, S, Andolfi, G, Mirolo, M, Brigida, I, Tabucchi, A, Carlucci, F, Eibl, M, Aker, M, Slavin, S, Al-Mousa, H, Al Ghonaium, A, Ferster, A, Duppenthaler, A, Notarangelo, L, Wintergerst, U, Buckley, R H, Bregni, M, Marktel, S, Valsecchi, M G, Rossi, P, Ciceri, F, Miniero, R, Bordignon, C \& Roncarolo, M G (2009) Gene therapy for immunodeficiency due to adenosine deaminase deficiency. N Engl J Med, 360, 447-58.

Arnett A L, Konieczny, P, Ramos, J N, Hall, J, Odom, G, Yablonka-Reuveni, Z, Chamberlain, J R \& Chamberlain, J S (2014) Adeno-associated viral vectors do not 
efficiently target muscle satellite cells. Molecular Therapy - Methods \& Clinical Development, 1, 14038.

Barthelemy F, Wein, N, Krahn, M, Levy, N \& Bartoli, M (2011) Translational research and therapeutic perspectives in dysferlinopathies. Mol Med, 17, 875-82.

Benedetti S, Hoshiya, H \& Tedesco, F S (2013) Repair or replace? Exploiting novel gene and cell therapy strategies for muscular dystrophies. FEBS J, 280, 4263-80.

Biasco L, Baricordi, C \& Aiuti, A (2012) Retroviral integrations in gene therapy trials. Mol Ther, 20, 709-16.

Biffi A, Montini, E, Lorioli, L, Cesani, M, Fumagalli, F, Plati, T, Baldoli, C, Martino, S, Calabria, A, Canale, S, Benedicenti, F, Vallanti, G, Biasco, L, Leo, S, Kabbara, N, Zanetti, G, Rizzo, W B, Mehta, N A, Cicalese, M P, Casiraghi, M, Boelens, J J, Del Carro, U, Dow, D J, Schmidt, M, Assanelli, A, Neduva, V, Di Serio, C, Stupka, E, Gardner, J, Von Kalle, C, Bordignon, C, Ciceri, F, Rovelli, A, Roncarolo, M G, Aiuti, A, Sessa, M \& Naldini, L (2013) Lentiviral hematopoietic stem cell gene therapy benefits metachromatic leukodystrophy. Science, 341, 1233158.

Blau H M, Webster, C \& Pavlath, G K (1983) Defective myoblasts identified in Duchenne muscular dystrophy. Proceedings of the National Academy of Sciences of the United States of America, 80, 4856-60.

Borchin B, Chen, J \& Barberi, T (2013) Derivation and FACS-Mediated Purification of PAX3+/PAX7+ Skeletal Muscle Precursors from Human Pluripotent Stem Cells. Stem Cell Reports, 1, 620-31.

Broderick M J \& Winder, S J (2005) Spectrin, alpha-actinin, and dystrophin. Adv Protein Chem, 70, 203-46.

Bulfield G, Siller, W G, Wight, P A \& Moore, K J (1984) X chromosome-linked muscular dystrophy (mdx) in the mouse. Proc Natl Acad Sci U S A, 81, 1189-92.

Cassano M, Dellavalle, A, Tedesco, F S, Quattrocelli, M, Crippa, S, Ronzoni, F, Salvade, A, Berardi, E, Torrente, Y, Cossu, G \& Sampaolesi, M (2011) Alpha sarcoglycan is required for FGF-dependent myogenic progenitor cell proliferation in vitro and in vivo. Development, 138, 4523-33.

Cogne B, Snyder, R, Lindenbaum, P, Dupont, J B, Redon, R, Moullier, P \& Leger, A (2014) NGS library preparation may generate artifactual integration sites of AAV vectors. Nat Med, 20, 577-8.

Cohn R D, Henry, M D, Michele, D E, Barresi, R, Saito, F, Moore, S A, Flanagan, J D, Skwarchuk, M W, Robbins, M E, Mendell, J R, Williamson, R A \& Campbell, K P (2002) Disruption of DAG1 in differentiated skeletal muscle reveals a role for dystroglycan in muscle regeneration. Cell, 110, 639-48. 
Darabi R, Arpke, R W, Irion, S, Dimos, J T, Grskovic, M, Kyba, M \& Perlingeiro, R C (2012) Human ES- and iPS-derived myogenic progenitors restore DYSTROPHIN and improve contractility upon transplantation in dystrophic mice. Cell Stem Cell, 10, 610-9.

Dellavalle A, Maroli, G, Covarello, D, Azzoni, E, Innocenzi, A, Perani, L, Antonini, S, Sambasivan, R, Brunelli, S, Tajbakhsh, S \& Cossu, G (2011) Pericytes resident in postnatal skeletal muscle differentiate into muscle fibres and generate satellite cells. Nat Commun, 2, 499.

Dellavalle A, Sampaolesi, M, Tonlorenzi, R, Tagliafico, E, Sacchetti, B, Perani, L, Innocenzi, A, Galvez, B G, Messina, G, Morosetti, R, Li, S, Belicchi, M, Peretti, G, Chamberlain, J S, Wright, W E, Torrente, Y, Ferrari, S, Bianco, P \& Cossu, G (2007) Pericytes of human skeletal muscle are myogenic precursors distinct from satellite cells. Nature cell biology, 9, 255-67.

Di Matteo M, Belay, E, Chuah, M K \& Vandendriessche, T (2012) Recent developments in transposon-mediated gene therapy. Expert Opin Biol Ther, 12, 841-58.

Diaz-Manera J, Touvier, T, Dellavalle, A, Tonlorenzi, R, Tedesco, F S, Messina, G, Meregalli, M, Navarro, C, Perani, L, Bonfanti, C, Illa, I, Torrente, Y \& Cossu, G (2010) Partial dysferlin reconstitution by adult murine mesoangioblasts is sufficient for full functional recovery in a murine model of dysferlinopathy. Cell Death Dis, 1, e61.

Flanigan K M, Campbell, K, Viollet, L, Wang, W, Gomez, A M, Walker, C M \& Mendell, J R (2013) Anti-dystrophin T cell responses in Duchenne muscular dystrophy: prevalence and a glucocorticoid treatment effect. Hum Gene Ther, 24, 797-806.

Fournier R E \& Ruddle, F H (1977) Microcell-mediated transfer of murine chromosomes into mouse, Chinese hamster, and human somatic cells. Proc Natl Acad Sci U S A, 74, 319-23.

Gang E J, Darabi, R, Bosnakovski, D, Xu, Z, Kamm, K E, Kyba, M \& Perlingeiro, R C (2009) Engraftment of mesenchymal stem cells into dystrophin-deficient mice is not accompanied by functional recovery. Exp Cell Res, 315, 2624-36.

Gaspar H B, Cooray, S, Gilmour, K C, Parsley, K L, Zhang, F, Adams, S, Bjorkegren, E, Bayford, J, Brown, L, Davies, E G, Veys, P, Fairbanks, L, Bordon, V, Petropoulou, T, Kinnon, C \& Thrasher, A J (2011) Hematopoietic stem cell gene therapy for adenosine deaminase-deficient severe combined immunodeficiency leads to long-term immunological recovery and metabolic correction. Sci Transl Med, 3, 97ra80.

Goudenege S, Lebel, C, Huot, N B, Dufour, C, Fujii, I, Gekas, J, Rousseau, J \& Tremblay, J P (2012) Myoblasts derived from normal hESCs and dystrophic 
hiPSCs efficiently fuse with existing muscle fibers following transplantation. Mol Ther, 20, 2153-67.

Hackett P B, Largaespada, D A, Switzer, K C \& Cooper, L J (2013) Evaluating risks of insertional mutagenesis by DNA transposons in gene therapy. Transl Res, 161, 265-83.

Harper S Q, Hauser, M A, Dellorusso, C, Duan, D, Crawford, R W, Phelps, S F, Harper, H A, Robinson, A S, Engelhardt, J F, Brooks, S V \& Chamberlain, J S (2002) Modular flexibility of dystrophin: implications for gene therapy of Duchenne muscular dystrophy. Nat Med, 8, 253-61.

Hoffman E P, Brown, R H, Jr. \& Kunkel, L M (1987) Dystrophin: the protein product of the Duchenne muscular dystrophy locus. Cell, 51, 919-28.

Hoshiya H, Kazuki, Y, Abe, S, Takiguchi, M, Kajitani, N, Watanabe, Y, Yoshino, T, Shirayoshi, Y, Higaki, K, Messina, G, Cossu, G \& Oshimura, M (2009) A highly stable and nonintegrated human artificial chromosome (HAC) containing the 2.4 Mb entire human dystrophin gene. Mol Ther, 17, 309-17.

Hsu P D, Lander, E S \& Zhang, F (2014) Development and applications of CRISPRCas9 for genome engineering. Cell, 157, 1262-78.

Kaeppel C, Beattie, S G, Fronza, R, Van Logtenstein, R, Salmon, F, Schmidt, S, Wolf, S, Nowrouzi, A, Glimm, H, Von Kalle, C, Petry, H, Gaudet, D \& Schmidt, M (2013) A largely random AAV integration profile after LPLD gene therapy. Nat Med, 19, 889-91.

Kazuki Y, Hiratsuka, M, Takiguchi, M, Osaki, M, Kajitani, N, Hoshiya, H, Hiramatsu, K, Yoshino, T, Kazuki, K, Ishihara, C, Takehara, S, Higaki, K, Nakagawa, M, Takahashi, K, Yamanaka, S \& Oshimura, M (2010) Complete genetic correction of ips cells from Duchenne muscular dystrophy. Mol Ther, 18, 386-93.

Kazuki Y, Hoshiya, H, Takiguchi, M, Abe, S, Iida, Y, Osaki, M, Katoh, M, Hiratsuka, M, Shirayoshi, Y, Hiramatsu, K, Ueno, E, Kajitani, N, Yoshino, T, Kazuki, K, Ishihara, C, Takehara, S, Tsuji, S, Ejima, F, Toyoda, A, Sakaki, Y, Larionov, V, Kouprina, N \& Oshimura, M (2011) Refined human artificial chromosome vectors for gene therapy and animal transgenesis. Gene Ther, 18, 384-93.

Kazuki Y \& Oshimura, M (2011) Human artificial chromosomes for gene delivery and the development of animal models. Mol Ther, 19, 1591-601.

Kononenko A V, Bansal, R, Lee, N C, Grimes, B R, Masumoto, H, Earnshaw, W C, Larionov, V \& Kouprina, N (2014) A portable BRCA1-HAC (human artificial chromosome) module for analysis of BRCA1 tumor suppressor function. Nucleic Acids Res, doi: 10.1093/nar/gku870.

Koo T, Popplewell, L, Athanasopoulos, T \& Dickson, G (2014) Triple transsplicing adeno-associated virus vectors capable of transferring the coding 
sequence for full-length dystrophin protein into dystrophic mice. Hum Gene Ther, 25, 98-108.

Kouprina N, Tomilin, A N, Masumoto, H, Earnshaw, W C \& Larionov, V (2014) Human artificial chromosome-based gene delivery vectors for biomedicine and biotechnology. Expert Opin Drug Deliv, 11, 517-35.

Kudryashova E, Kramerova, I \& Spencer, M J (2012) Satellite cell senescence underlies myopathy in a mouse model of limb-girdle muscular dystrophy $2 \mathrm{H}$. The Journal of clinical investigation, 122, 1764-76.

Kurosaki H, Hiratsuka, M, Imaoka, N, Iida, Y, Uno, N, Kazuki, Y, Ishihara, C, Yakura, Y, Mimuro, J, Sakata, Y, Takeya, H \& Oshimura, M (2011) Integration-free and stable expression of FVIII using a human artificial chromosome. J Hum Genet, 56, 727-33.

Maffioletti S M, Noviello, M, English, K \& Tedesco, F S (2014) Stem cell transplantation for muscular dystrophy: the challenge of immune response. Biomed Res Int, 2014, 964010.

Mandegar M A, Moralli, D, Khoja, S, Cowley, S, Chan, D Y, Yusuf, M, Mukherjee, S, Blundell, M P, Volpi, E V, Thrasher, A J, James, W \& Monaco, Z L (2011) Functional human artificial chromosomes are generated and stably maintained in human embryonic stem cells. Hum Mol Genet, 20, 2905-13.

Mavilio F, Pellegrini, G, Ferrari, S, Di Nunzio, F, Di Iorio, E, Recchia, A, Maruggi, G, Ferrari, G, Provasi, E, Bonini, C, Capurro, S, Conti, A, Magnoni, C, Giannetti, A \& De Luca, M (2006) Correction of junctional epidermolysis bullosa by transplantation of genetically modified epidermal stem cells. Nat Med, 12, 1397-402.

Mendell J R, Campbell, K, Rodino-Klapac, L, Sahenk, Z, Shilling, C, Lewis, S, Bowles, D, Gray, S, Li, C, Galloway, G, Malik, V, Coley, B, Clark, K R, Li, J, Xiao, X, Samulski, J, Mcphee, S W, Samulski, R J \& Walker, C M (2010a) Dystrophin immunity in Duchenne's muscular dystrophy. N Engl J Med, 363, 1429-37.

Mendell J R, Rodino-Klapac, L R, Rosales, X Q, Coley, B D, Galloway, G, Lewis, S, Malik, V, Shilling, C, Byrne, B J, Conlon, T, Campbell, K J, Bremer, W G, Taylor, L E, Flanigan, K M, Gastier-Foster, J M, Astbury, C, Kota, J, Sahenk, Z, Walker, C M \& Clark, K R (2010b) Sustained alpha-sarcoglycan gene expression after gene transfer in limb-girdle muscular dystrophy, type 2D. Ann Neurol, 68, 629-38.

Mercuri E \& Muntoni, F (2013) Muscular dystrophies. Lancet, 381, 845-60.

Minasi M G, Riminucci, M, De Angelis, L, Borello, U, Berarducci, B, Innocenzi, A, Caprioli, A, Sirabella, D, Baiocchi, M, De Maria, R, Boratto, R, Jaffredo, T, Broccoli, V, Bianco, P \& Cossu, G (2002) The meso-angioblast: a multipotent, self-renewing cell that originates from the dorsal aorta and differentiates into most mesodermal tissues. Development, 129, 2773-83. 
Muntoni F, Torelli, S \& Ferlini, A (2003) Dystrophin and mutations: one gene, several proteins, multiple phenotypes. Lancet Neurol, 2, 731-40.

Muntoni F \& Wood, M J (2011) Targeting RNA to treat neuromuscular disease. Nat Rev Drug Discov, 10, 621-37.

Naldini L (2011) Ex vivo gene transfer and correction for cell-based therapies. Nat Rev Genet, 12, 301-15.

Narayanan G, Cossu, G, Galli, M C, Flory, E, Ovelgonne, H, Salmikangas, P, Schneider, C K \& Trouvin, J H (2014) Clinical development of gene therapy needs a tailored approach: a regulatory perspective from the European Union. Hum Gene Ther Clin Dev, 25, 1-6.

Partridge T (2002) Myoblast transplantation. Neuromuscul Disord, 12 Suppl 1, S3-6.

Partridge T A, Morgan, J E, Coulton, G R, Hoffman, E P \& Kunkel, L M (1989) Conversion of mdx myofibres from dystrophin-negative to -positive by injection of normal myoblasts. Nature, 337, 176-9.

Rama P, Matuska, S, Paganoni, G, Spinelli, A, De Luca, M \& Pellegrini, G (2010) Limbal stem-cell therapy and long-term corneal regeneration. N Engl J Med, 363, 147-55.

Sacco A, Mourkioti, F, Tran, R, Choi, J, Llewellyn, M, Kraft, P, Shkreli, M, Delp, S, Pomerantz, J H, Artandi, S E \& Blau, H M (2010) Short telomeres and stem cell exhaustion model Duchenne muscular dystrophy in mdx/mTR mice. Cell, 143, 1059-71.

Schultz B R \& Chamberlain, J S (2008) Recombinant adeno-associated virus transduction and integration. Mol Ther, 16, 1189-99.

Singh H, Figliola, M J, Dawson, M J, Olivares, S, Zhang, L, Yang, G, Maiti, S, Manuri, P, Senyukov, V, Jena, B, Kebriaei, P, Champlin, R E, Huls, H \& Cooper, L J (2013) Manufacture of clinical-grade CD19-specific T cells stably expressing chimeric antigen receptor using Sleeping Beauty system and artificial antigen presenting cells. PLoS One, 8, e64138.

Skuk D \& Tremblay, J P (2014) Clarifying misconceptions about myoblast transplantation in myology. Mol Ther, 22, 897-8.

Smith R H (2008) Adeno-associated virus integration: virus versus vector. Gene Ther, 15, 817-22.

Tanaka A, Woltjen, K, Miyake, K, Hotta, A, Ikeya, M, Yamamoto, T, Nishino, T, Shoji, E, Sehara-Fujisawa, A, Manabe, Y, Fujii, N, Hanaoka, K, Era, T, Yamashita, S, Isobe, K, Kimura, E \& Sakurai, H (2013) Efficient and reproducible myogenic 
differentiation from human iPS cells: prospects for modeling Miyoshi Myopathy in vitro. PLoS One, 8, e61540.

Tedesco F S, Dellavalle, A, Diaz-Manera, J, Messina, G \& Cossu, G (2010) Repairing skeletal muscle: regenerative potential of skeletal muscle stem cells. J Clin Invest, 120, 11-9.

Tedesco F S, Gerli, M F, Perani, L, Benedetti, S, Ungaro, F, Cassano, M, Antonini, S, Tagliafico, E, Artusi, V, Longa, E, Tonlorenzi, R, Ragazzi, M, Calderazzi, G, Hoshiya, H, Cappellari, O, Mora, M, Schoser, B, Schneiderat, P, Oshimura, M, Bottinelli, R, Sampaolesi, M, Torrente, Y, Broccoli, V \& Cossu, G (2012) Transplantation of Genetically Corrected Human iPSC-Derived Progenitors in Mice with Limb-Girdle Muscular Dystrophy. Science translational medicine, 4, 140ra89.

Tedesco F S, Hoshiya, H, D'antona, G, Gerli, M F, Messina, G, Antonini, S, Tonlorenzi, R, Benedetti, S, Berghella, L, Torrente, Y, Kazuki, Y, Bottinelli, R, Oshimura, M \& Cossu, G (2011) Stem cell-mediated transfer of a human artificial chromosome ameliorates muscular dystrophy. Sci Transl Med, 3, 96ra78.

Uno N, Uno, K, Zatti, S, Ueda, K, Hiratsuka, M, Katoh, M \& Oshimura, M (2013) The transfer of human artificial chromosomes via cryopreserved microcells.

Cytotechnology, 65, 803-9.

Xu C, Tabebordbar, M, Iovino, S, Ciarlo, C, Liu, J, Castiglioni, A, Price, E, Liu, M, Barton, E R, Kahn, C R, Wagers, A J \& Zon, L I (2013) A zebrafish embryo culture system defines factors that promote vertebrate myogenesis across species. Cell, $155,909-21$.

Zatti S, Martewicz, S, Serena, E, Uno, N, Giobbe, G, Kazuki, Y, Oshimura, M \& Elvassore, $\mathrm{N}$ (2014) Complete restoration of multiple dystrophin isoforms in genetically corrected Duchenne muscular dystrophy patient-derived cardiomyocytes. Molecular Therapy - Methods \& Clinical Development, 1, doi: 10.1038/mtm.2013.1. 